\title{
Estimation of additive and epistatic genetic variances for agronomic traits in a population of doubled-haploid lines of wheat
}

\author{
I. GOLDRINGER ${ }^{*} \dagger, P$. BRABANT $\dagger+\&$ A. GALLAIS $\uparrow \ddagger$ \\ $\dagger$ †tation de Génétique Végétale, Ferme du Moulon, 91190 Gif sur Yvette and $\ddagger$ INA-PG, 16 rue Claude Bernard, 75005 \\ Paris, France
}

\begin{abstract}
In order to determine a selection strategy for a population of winter wheat subjected to recurrent selection, we assessed the relative extent of both additive and epistatic effects for agronomic traits involved in yield performance. The partitioning (between and within mother plant) of the genetic variance in doubled-haploid lines derived from the intercrossed population provided estimates of additive and epistatic additive $\times$ additive variances at the pure line level. Two similar experiments with 56 lines in 1992 and with 73 in 1993 were conducted at Gif sur Yvette in France. Results showed that 1993 was less favourable for yield performance than 1992. Even when genotype-by-year interactions were found significant, both genetic effects (between plants, between lines within plants) were consistent from one year to the other, and the ratios of variances appeared rather homogeneous over years. Earliness and powdery mildew resistance showed a large epistatic variance. Plant height seemed to be quite additive; this certainly could be related to the presence of two major dwarfing genes polymorphic in the population. Morphological traits of the spike showed larger additive than epistatic variance. Yield components measured on the spike either were predominantly additive or displayed both additive and epistatic effects. For grain yield, which is the most integrative trait, we found larger epistatic than additive variance. The genetic control of a given trait cannot be definitively characterized because it depends on the genetic material, the test system and the environmental conditions. However, our results show the importance of epistasis especially in the genetic control of complex traits.
\end{abstract}

Keywords: agronomic traits, bread wheat, doubled-haploid, epistasis, quantitative genetics, Triticum aestivum (L).

\section{Introduction}

In breeding programmes, inbred families are often produced and evaluated as possible varieties or as parents of hybrids. For quantitative traits, the structure of genetic variability among inbred families at different generations of selfing depends on the way genes act and varies according to the trait selected. Given that in most crops, many economically important traits such as yield, earliness and quality are quantitatively inherited, selection strategies must be optimized according to the relative importance of the variance components, the reproductive system of the species and the type of variety which is selected for. Particularly, the knowledge of the relative proportion of nonadditive variance with respect to

${ }^{*}$ Correspondence. E-mail: isa@moulon.inra.fr additivity of a selected trait is necessary for choosing a recurrent selection scheme. Progenies derived from simple mating designs (hierarchical, factorial or diallel) have been widely used to estimate additive and dominance variances. In the absence of epistasis, these estimates may allow the prediction of expected genetic advance for per se or combining ability values in cross-pollinated crops as shown by Gallais (1993).

Likewise, it is important to consider the proportion of between-locus interactions (epistasis) with regard to additive variation. In fact, epistasis could be expected to be quite important in self-pollinated crops because of selection history on a fixed genome with only few recombination events. Griffing (1960) and later Cockerham (1984) have shown that the additive-by-additive epistatic variance, which contributes to the initial response to selection in an 
outbred population, declines with continued random mating if the recombinant fraction is greater than zero. Designs specific to the study of epistatic components often involve complex procedures. Hayman (1958) has proposed a generation means model, with six generations derived from a cross between two inbred lines, to estimate the six genetic parameters (mean, additivity, dominance and the three types of epistasis). Another widely used way to detect epistatic variation is the triple test-cross as defined by Kearsey \& Jinks (1968) as well as the derived simplified test for inbred lines (Jinks et al., 1969). The latter is better suited to self-pollinated crops but might lead to ambiguous tests if the two testers are not adequate (Virk \& Jinks, 1977). Chahal \& Jinks (1978) further proposed a singletester design with a test for epistasis based on the standard BC scaling tests (Mather \& Jinks, 1971) which avoids the consequences of using inadequate testers. All these tests are based on the comparison of means and assume a biallelic genetic model. The derivation of doubled-haploid lines from a diallel cross (Choo et al., 1979) or from a random mating design (Gallais, 1990) provides a well adapted and simple design to detect epistasis at the variances level.

In an inbred population, additional variance components related to the interaction effects between identical alleles (homozygous dominance) are needed to describe all the variation involved at the homozygous level (Gillois, 1964; Harris, 1964; Gallais, 1970, 1974; Cornelius, 1975). Choo et al. (1979) and Snape \& Simpson (1981) have presented a model for genetic values and variances of pure-line populations in the biallelic case. Gallais (1979) has shown, in a more general case, that the concept of line value and genetic effects for line value simplifies the model (only two parameters of variance) and generalizes the approach for line populations. Gallais (1990) has given the expression of the line value of a genotype for many loci with epistasis. According to this approach, we used a simple nested design with $\ell$ lines derived from $p$ plants taken from an intercrossed wheat population in order to estimate the genetic parameters of the population with special attention to additive and epistatic additiveby-additive variance components at the pure line level. The aim of the study was: (i) to assess the relative extent of both additive and epistatic effects for agronomic traits involved in yield elaboration in a population of winter wheat; (ii) to draw some general conclusions (if any) from bibliographic data concerning the determinism of these traits in selfpollinated cereal crops (especially for wheat); and (iii) to discuss briefly the choice of a selection strategy for the traits studied.

\section{Materials and methods}

Two similar experiments were conducted at the 'Station de Génétique Végétale', Le Moulon, France, in 1992 and 1993. In 1992, the material (sample 1) included 56 doubled-haploid lines derived by in vitro androgenesis from $21 \mathrm{~S}_{0}$ plants with at least two lines per plant (average of 2.7 lines per $S_{0}$ plant). In 1993, the material (sample 2) consisted of 73 doubled-haploid lines derived from $24 \mathrm{~S}_{0}$ plants (average of three lines per $\mathrm{S}_{0}$ plant), 49 of which were already in sample 1 . The $S_{0}$ plants had been taken at random from a population obtained after two successive generations of random crossing between the families selected at the third cycle of a recurrent selection scheme (Thomas et al., 1991). This $\mathrm{S}_{0}$ population was considered as the reference panmictic population. Each line sample was grown in a randomized complete block design with two replications. For each line, the plot was a six-row plot of $4 \mathrm{~m}$ long $\times 1.5 \mathrm{~m}$ wide. Seeds were sown to obtain a density of 250 plants/square metre after the winter. Both trials were conducted under the intensive cultural conditions of the area but without growth regulator application. Five French varieties (Arminda, Camp Remy, Festival, Fidel, Pernel) were used as controls. The traits measured were of two kinds: (i) observations recorded on the whole plot: grain yield at 15 per cent of moisture ( $\mathrm{qx} / \mathrm{ha}$ ) (GY), powdery mildew attack (scale from 1, resistant to 9 according to the severity of the symptoms) (PM), heading date (days from the first of May) (HD) and plant height $(\mathrm{cm})(\mathrm{PH})$; and (ii) observations recorded on 10 sound ears cut in each plot before harvest: ear length $(\mathrm{cm})$ (EL), number of kernels per spike $(\mathrm{NK} / \mathrm{S})$, number of spikelets per spike (NSplt/S), number of kernels per spikelet (NK/Splt), grain weight per spike $(\mathrm{GW} / \mathrm{S})$ and weight of 1000 kernels (KW).

From both experiments, the between $S_{0}$ plants genetic variance $\left(\sigma_{G L B}^{2}\right)$ as well as the between line within $\mathrm{S}_{0}$ plant variance $\left(\sigma_{G L W}^{2}\right)$ were assessed by analysis of variance with a classical mixed nested model. The analysis of variance was also performed on the sample of lines grown for the two years, 49 lines and $18 \mathrm{~S}_{0}$ plants (intersection sample), with the following complete model:

$$
\begin{aligned}
Y_{i j k l}= & \mu+y e_{i}+b l / y e_{i j}+B_{k}+W_{k l}+(B * y e)_{i k} \\
& +(W * y e)_{i k l}+E_{i j k l}
\end{aligned}
$$


where ye is the fixed year effect, bl/ye the fixed block effect, $B$ and $W$ the random genetic effects (between plants and between lines within plants), and ( $B * y e)$ and $(W * y e)$ the two year-by-genotype random interactions. Estimates of genetic variances for each set of data (samples 1,2 and intersection), as well as variances of interaction for the intersection sample, were obtained with a restricted maximum likelihood procedure (VARCOMP option REML of SAS software). The maximum likelihood procedure provided an estimated asymptotic covariance matrix of variance components; standard errors for the estimated variances as well as for the additive and epistatic variance components could then be inferred straightforwardly.

According to the theory of Gallais (1990), $\sigma_{G L B}^{2}=\sigma_{A L}^{2}+\sigma_{A A L}^{2}$ and $\sigma_{G L W}^{2}=\sigma_{A L}^{2}+\sigma_{A A L}^{2}$, where $\sigma_{A L}^{2}$ and $\sigma_{A A L}^{2}$ are the additive and the epistatic additiveby-additive variances at the pure line level, respectively. The total genetic variance between all the lines derived from the $S_{0}$ population is then:

$\sigma_{G L}^{2}=\sigma_{G L B}^{2}+\sigma_{G L W}^{2}=2 \sigma_{A L}^{2}+4 \sigma_{A A L}^{2}$.

According to the model, $\sigma_{A L}^{2}$ and $\sigma_{A A L}^{2}$ are not equal to $\sigma_{A}^{2}$ and $\sigma_{A A}^{2}$, additive and epistatic additive-byadditive variances in the panmictic population, respectively, because they include components related to residual homozygous dominance effects (Gallais, 1990). Development of the variances at the pure line level and equivalents in other models were given in Goldringer et al. (1996). Estimates of $\sigma_{A L}^{2}$ and $\sigma_{A A L}^{2}$ were computed as follows:

$\hat{\sigma}_{A L}^{2}=\frac{1}{2}\left(3 \hat{\sigma}_{G L B}^{2}-\hat{\sigma}_{G L W}^{2}\right)$,

$\hat{\sigma}_{A A L}^{2}=\frac{1}{2}\left(\hat{\sigma}_{G L W}^{2}-\hat{\sigma}_{G L B}^{2}\right)$.

Broad sense heritabilities on a mean basis $\left(h_{B S}^{2}=\sigma_{G L}^{2} /\left(\sigma_{G L}^{2}+\frac{1}{b} \sigma_{R}^{2}\right)\right.$, where $\sigma_{R}^{2}$ is the residual variance associated with the experimental design and $b$ the number of replications (in our case $b=2$ )), variation coefficients and genetic correlations were inferred from the simple two-factor (line and block) ANOVA model instead of the nested model. Neglecting the nested structure led to the following biased estimation of $\sigma_{G L}^{2}$ :

$\hat{\sigma}_{G L}^{2}=\hat{\sigma}_{G L}^{2}-\frac{(\ell-1)}{(p \ell-1)} \hat{\sigma}_{G L B}^{2}$

In our case, with $\ell=2.7$ or 3 and $p=21$ or 24 , the bias was negligible. Confidence intervals on heritabilities were obtained according to the formulation of Knapp et al. (1985). Computing the multivariate analysis of variance with the same two-factor model, we estimated the genetic correlation coefficient $\hat{r}_{G L}$ between traits. Approximate standard errors (SE) on $\hat{r}_{G L}$ were derived using the formula given by Scheinberg (1966) and Becker (1984). As the distribution of $r_{G L}$ is not known, we arbitrarily considered $\hat{r}_{G L}$ as significant when its absolute value was greater than twice its standard error.

To test the difference between environmental conditions of the years 1992 and 1993, we computed the adjusted means $(\bar{m}(92)$ and $\bar{m}(93))$ on the intersection file for all the traits. The relative difference of means $(\Delta)$ was inferred as follows: $\Delta=(\bar{m}(93)-\bar{m}(92)) / \bar{m}(92)$.

The genetic and environmental coefficients of variation $\left(C V_{g}\right.$ and $\left.C V_{e}\right)$ as well as the relative difference of means were not calculated for heading date and powdery mildew because the values of these traits were expressed on an arbitrary scale.

In the following, between-plant effect or variance and between-line within-plant effect or variance are referred to as $B$ and $W$, respectively.

\section{Results and discussion}

The analysis of variance with the complete model on the intersection sample showed a significant year effect for every trait (Table 1). Grain yield (GY), ear length (ER), number of spikelets per spike $(\mathrm{NSplt} / \mathrm{S})$, number of kernels per spike (NK/S), number of kernels per spikelet (NK/Splt), grain weight per spike $(\mathrm{GW} / \mathrm{S})$ and kernel weight $(\mathrm{KW})$ were lower in 1993 compared to 1992. Plant height (PH) was higher, heading date (HD) was earlier and powdery mildew attack (PM) was lower. The year effect indicated that 1993 had been less favourable than 1992 for yield expression. All the yield components were affected. Ear fertility measured by $\mathrm{NK} / \mathrm{Splt}$ and $\mathrm{NK} / \mathrm{S}$ was more affected than mean grain weight. This led to the conclusion that the main limiting factors occurred at meiosis and/or pollination. Genotype-by-year interactions were always significant for at least one of the two genetic effects (Table 2). This will be discussed later in this section. However, there was always at least one significant genetic effect so that the genetic analysis remained meaningful.

For all traits, estimates of heritabilities were very high and they were not significantly different between both years except for plant height and number of spikelets per spike (Table 3). For the latter, heritability was slightly lower in 1993 than in 1992. Generally speaking, environmental variation was larger in 1993. This may be related to the bad meteorological conditions during early summer 
Table 1 Adjusted means of genotypes for the years 1992 and 1993, relative differences and probability for $t$-test, on the intersection file, for traits measured on two trials of doubled-haploid lines of wheat

\begin{tabular}{lrrrr}
\hline & \multicolumn{2}{c}{ Adjusted means } & & \\
\cline { 2 - 3 } Traits & $\bar{m}(92)$ & $\bar{m}(93)$ & $\Delta \%$ & $P(t)$ \\
\hline HD & 24.73 & 20.64 & - & 0.0001 \\
PH & 89.91 & 94.66 & +5.28 & 0.0012 \\
PM & 6.99 & 4.49 & - & 0.0001 \\
EL & 97.98 & 84.19 & -14.07 & 0.0001 \\
NSplt/S & 19.23 & 18.75 & -2.50 & 0.0347 \\
NK/S & 58.44 & 47.33 & -19.01 & 0.0001 \\
NK/Splt & 3.03 & 2.51 & -17.16 & 0.0001 \\
GW/S & 2.54 & 1.91 & -24.80 & 0.0001 \\
KW & 44.10 & 40.49 & -8.19 & 0.0001 \\
GY & 61.63 & 53.46 & -13.26 & 0.0001 \\
\hline
\end{tabular}

$\mathrm{HD}$, heading date; $\mathrm{PH}$, plant height; $\mathrm{PM}$, powdery mildew; EL, ear length; NSplt/S, number of spikelets per spike; NK/S, number of kernels per spike; NK/Splt, number of kernels per spikelet; GW/S, grain weight per spike; KW, 1000 kernel weight; GY, grain yield.

$\Delta=\frac{\bar{m}(93)-\bar{m}(92)}{\bar{m}(92)}$.

— stands for $\Delta \%$ not calculated (see text).

in 1993. Anyway, the control of the experimental conditions was quite good in 1992, and hardly less satisfactory in 1993. The genetic variation coefficients were homogeneous between the two years except for plant height. Their relatively high values $(\approx 15$ per cent) for yield and yield components proved that the population under selection was highly polymorphic for these traits. The high heritabilities observed are the consequence of the great genetic variability but also of the large experimental plots used. In early selection, lines are often tested with small plots reduced to a single row or a hillplot. This leads to poorer experimental variation control and lower heritabilities. In previous experiments with single-row plots, we estimated a value of 0.51 for yield heritability on the basis of the mean over three replicates (Goldringer et al., 1994) and values ranging from 0.56 to 0.64 (Brabant et al., 1989) on means over two replicates.

Genetic correlations between traits were rather similar between both years (Table 4) indicating that the genotype-by-environment interaction was not strong enough to disturb significantly the relation- ships between traits. The main discrepancy was for kernel weight $(\mathrm{KW})$ which was genetically correlated with grain weight per spike $(\mathrm{GW} / \mathrm{S})$ and grain yield (GY) $(+0.51$ and +0.42 , respectively) in 1993 but not in 1992. At each cycle of recurrent selection the correlation between $\mathrm{KW}$ and GY was always found either low or null (Brabant et al., 1989and unpublished data). The general feature under North European oceanic conditions seems to be the absence of genetic correlation between those two traits (Ledent, 1982). The moderate relationship found in 1993 could indicate that some genotypes partially compensated for the general loss of fertility resulting from the year conditions by higher KW when others did not. These variable abilities to compensate could be related to differences between genotypes in their maximum kernel weight. Unfortunately, this trait can not be easily estimated on a large collection of genotypes. Given the fact that KW was affected by the year effect, we may also suppose that the genotypes had a differential sensitivity to the limiting factor affecting the grain filling period. It should be noted that NK/Splt and GW/S, which correspond to the notion of ear fertility often used by breeders, are the yield components showing the highest (though moderate: $r \approx 0.5$ ) genetic correlation with yield. This led us to the conclusion that an early selection on ear fertility should induce a moderate positive correlative response on yield. Correlations between $\mathrm{PH}$ and NK/S, NK/Splt, KW, GY could be related to pleiotropic effects of the dwarfing genes Rht1 and Rht2 as observed by McClung et al. (1986). However, as underlined by McClung et al. (1986), the literature reports conflicting results on the existence and the direction of these effects.

Estimations of between-plant $(B)$ and betweenline within-plant $(W)$ genetic variances are given in Table 2 with standard errors. The $W$ effect was always significant for all traits. The $B$ effect was not significant in at least one of the three samples for heading date (HD), powdery mildew (PM), number of kernels per spike (NK/S), grain weight per spike $(\mathrm{GW} / \mathrm{S})$ and grain yield (GY). In these cases, it follows from the model that, if $\hat{\sigma}_{G L B}^{2}$ is not significantly different from zero, both $\hat{\sigma}_{A L}^{2}$ and $\hat{\sigma}_{A A L}^{2}$ have to be equal to zero as well. Thus, when the $B$ effect was not significant at least at the 10 per cent level, we dropped calculations of the additive and epistatic genetic variances. In any case, these were leading to a negative estimation of the additive variance and to a high value for the epistatic variance. It should be noted that the nested structure involves higher power for the detection of the between lines within plants effect than for between mother plants effects, 


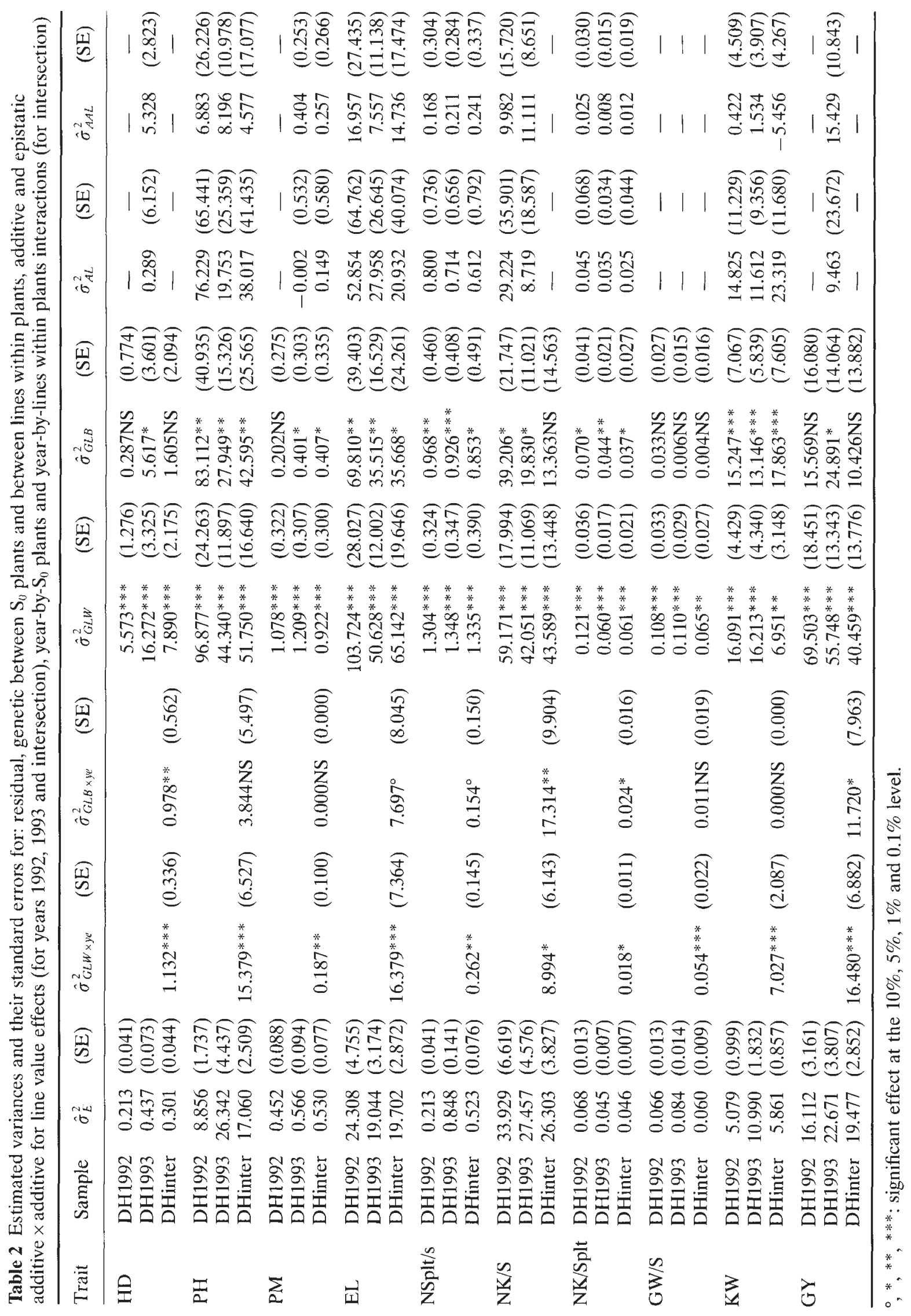


Table 3 Broad sense heritabilities and 95 per cent confidence intervals, genetic and environmental coefficients of variation for the two trials of double-haploid lines of wheat

\begin{tabular}{|c|c|c|c|c|c|c|c|c|}
\hline \multirow[b]{2}{*}{ Trait } & \multicolumn{4}{|c|}{$h_{B S}^{2}$} & \multicolumn{2}{|c|}{$C V_{g}(\%)^{1}$} & \multicolumn{2}{|c|}{$C V_{e}(\%)^{2}$} \\
\hline & 1992 & & 1993 & & 1992 & 1993 & 1992 & 1993 \\
\hline HD & 0.98 & {$[0.97 ; 0.99]$} & 0.99 & {$[0.98 ; 0.99]$} & - & - & - & - \\
\hline $\mathrm{PH}$ & 0.97 & {$[0.95 ; 0.98]$} & 0.84 & {$[0.74 ; 0.90]$} & 14.2 & 8.7 & 3.2 & 5.3 \\
\hline PM & 0.84 & {$[0.73 ; 0.91]$} & 0.85 & {$[0.76 ; 0.90]$} & - & - & - & - \\
\hline & 0.93 & {$[0.88 ; 0.96]$} & 0.90 & {$[0.84 ; 0.94]$} & 13.7 & 11.1 & 5.1 & 5.3 \\
\hline NSplt/S & 0.95 & {$[0.92 ; 0.97]$} & 0.86 & {$[0.77 ; 0.91]$} & 8.2 & 8.6 & 2.5 & 4.9 \\
\hline $\mathrm{NK} / \mathrm{S}$ & 0.85 & {$[0.73 ; 0.91]$} & 0.82 & {$[0.71 ; 0.89]$} & 16.9 & 16.7 & 10.0 & 11.1 \\
\hline NK/Splt & 0.85 & {$[0.73 ; 0.91]$} & 0.82 & {$[0.72 ; 0.89]$} & 14.5 & 12.8 & 8.6 & 8.4 \\
\hline GW/S & 0.79 & {$[0.65 ; 0.88]$} & 0.73 & {$[0.57 ; 0.83]$} & 14.9 & 18.6 & 10.5 & 15.9 \\
\hline KW & 0.92 & {$[0.87 ; 0.96]$} & 0.85 & {$[0.76 ; 0.91]$} & 13.2 & 14.4 & 5.2 & 8.5 \\
\hline GY & 0.91 & {$[0.84 ; 0.94]$} & 0.88 & {$[0.80 ; 0.92]$} & 14.9 & 17.1 & 6.6 & 9.1 \\
\hline
\end{tabular}

and that additionally if $\sigma_{A A L}^{2}$ is different from zero, $\sigma_{G L W}^{2}$ is expected to be larger and hence easier to detect than $\sigma_{G L B}^{2}$.

Significance of both $B$ and $W$ genetic effects were rather consistent from one year to the other. The complete model on the intersection file gave levels of significance either intermediate between those of the two years or lower. The loss of significance for one genetic effect in the intersection file is often related to a significant interaction of this effect with year (EL, NSplt/S, NK/S, NK/Splt, KW). Genotypeby-year interactions seemed to disturb more the between-plant part of the genetic variance than the within-plant part. Estimates of epistatic variances seemed to be more stable over the years than additive variances. Absolute values of variance estimations may vary but the ratios $\sigma_{G L B}^{2} /\left(\sigma_{G L B}^{2}+\sigma_{G L W}^{2}\right)$ appeared more homogeneous over the years (calculations not shown). Some traits (PH, EL, NSplt/S, $\mathrm{NK} / \mathrm{Splt}$ ) showed very stable ratios of genetic variances even if some of them display significant genotype-by-year interaction effects. Kernel weight lost a large part of the between-line within-plant variation in the intersection analysis. However, results on the additive and epistatic components of variance were still strengthened. On the other hand, number of kernels per spike (NK/S) showed a significant between-plant effect each year, and no effect in the intersection.

Traits may be classified into four types: morphological and pathological traits related to whole plant behaviour (HD, PH, PM), morphological features of the spike (EL, NSplt/S) and yield components at the spike level (NK/S, NK/Splt, GW/S, KW) measured on sound spikes and hence nearer to the potential of the genotype, and productivity measured at the plot level (GY). Heading date showed a large epistatic variance. Some of the mechanisms involved in ear emergence (vernalization requirement, sensitivity to photoperiod and temperature (Masle et al., 1989)) could work with threshold effects and hence display epistasis. The hexaploid nature of wheat could also be invoked to generate epistasis with for example the case of the three genes controlling vernalization requirements $(V m 1, V m 4$ and $V m 3)$, located on chromosome 5A, 5B and 5D, respectively (Xin et al., 1988). Epistasis is quite often detected for heading date in the literature concerned with cereal crops: we counted up to 10 cases among 13 experiments (or crosses) on wheat and five cases out of eight on barley and oats (Table 5). Large epistatic variance was also found for powdery mildew resistance. This could be explained by the genetic mechanisms of resistance in wheat. A specific resistance controlled by more than 20 genes is involved at the juvenile stage and a more quantitative resistance is developed at the adult stage when specific resistance is defeated. Under natural conditions, plants are contaminated with mixtures of pathogen races. Thus a specific combination of resistance genes may give a total immunity when the lack of one gene allows the disease to develop. Experiments on the behaviour of 
Table 4 Genetic correlation coefficients estimated for trial 1 (1992) and for trial 2 (1993) (the first and the second line in each trait entry, respectively)

\begin{tabular}{lccccccccc}
\hline Trait & HD & PH & PM & EL & NSplt/S & NK/S & NK/Splt GW/S & KW & GY \\
\hline PH & NS & & & & & & & & \\
& NS & & & & & & & & \\
PM & NS & NS & & & & & & & \\
& NS & NS & & & & & & & \\
EL & NS & +0.28 & NS & & & & & & \\
& NS & NS & NS & & & & & & \\
NSplt/S & +0.45 & NS & NS & NS & & & & & \\
& NS & NS & NS & +0.26 & & & & & \\
NK/S & NS & -0.30 & NS & +0.35 & +0.56 & & & & \\
& NS & -0.42 & NS & +0.35 & +0.64 & & & & \\
NK/Splt & NS & -0.38 & NS & +0.27 & NS & +0.87 & & & \\
& NS & -0.43 & NS & +0.26 & NS & +0.85 & & & \\
GW/S & NS & NS & NS & +0.33 & NS & +0.64 & +0.63 & & \\
& -0.30 & NS & NS & +0.29 & NS & +0.60 & +0.58 & & \\
KW & -0.45 & +0.47 & NS & NS & -0.43 & -0.57 & -0.43 & NS & \\
& -0.34 & +0.34 & NS & NS & -0.33 & -0.37 & -0.25 & +0.51 & \\
GY & NS & -0.38 & NS & NS & NS & +0.51 & +0.57 & +0.53 & NS \\
& -0.38 & -0.33 & NS & NS & -0.22 & NS & +0.43 & +0.54 & +0.42 \\
\hline
\end{tabular}

NS, nonsignificant value (see text).

wheat plants against pathogens showed epistasis for the adult stage resistance to leaf blight (Sinha et al., 1991) and interactions between specific resistance genes as well as nucleocytoplasmic interactions for stripe rust (Chen \& Line, 1992) (Table 5). In the transfer of alien chromosome segments in wheat, Hanušová et al. (1996) provided evidence for the inhibition of the resistant gene to powdery mildew $P m 8$ by a dominant suppressor.

The genetic control of plant height seemed to be quite additive. This was probably related to the presence of two major polymorphic dwarfing genes (Rht 1 and $R h t 2)$ in the population. Results from the literature about this trait are rather varied (nine cases of epistasis out of 13 experiments) but the authors do not give information about the presence of any segregating dwarfing genes in the tested populations.

The two morphological features of the spike (EL, NSplt/S) showed a larger additive than epistatic variance. In the literature, three experiments out of five on wheat detected epistasis for ear length, and the authors almost never found epistasis for number of spikelets per spike. In our experiment, the yield components measured on spikes were intermediate $(\mathrm{NK} / \mathrm{S}, \mathrm{NK} / \mathrm{Splt})$ or additive $(\mathrm{KW})$. This was consist- ent with other results for kernel weight in wheat experiments: only seven experiments among 17 led to the detection of epistasis. For grain yield we found a larger epistatic than additive variance. This result was supported by data from the literature (epistasis detected in 15 experiments out of 18).

\section{Conclusion}

Estimating the genetic variance components or detecting the associated effects strongly depends on the genetic material which is evaluated. Variance estimations can also depend on the test system used in the experiment. Nanda et al. (1989) have for example simultaneously carried out a triple testcross and a generation means study with the same initial parental lines for the crosses. They found slightly different results from one test system to another. New methods are now available to study the genetic basis of quantitative traits. Recent development of DNA markers has made it possible to locate some of the loci (QTL) controlling quantitative variation. In specific designs for QTL identification, epistasis between pairs of markers may also be searched for. Significant associations may be found between two markers, whether they are linked 


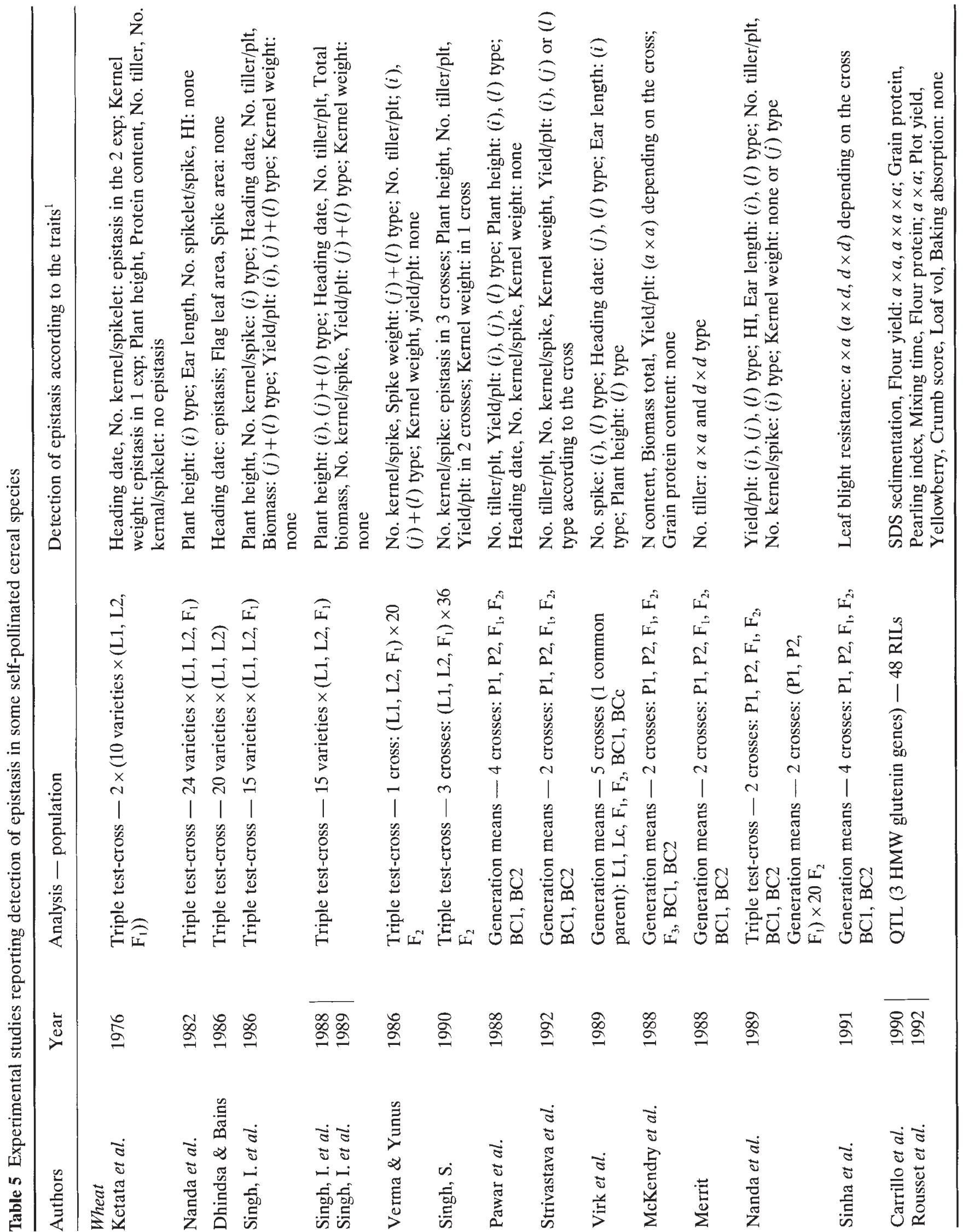

(C) The Genetical Society of Great Britain, Heredity, 79, 60-71. 


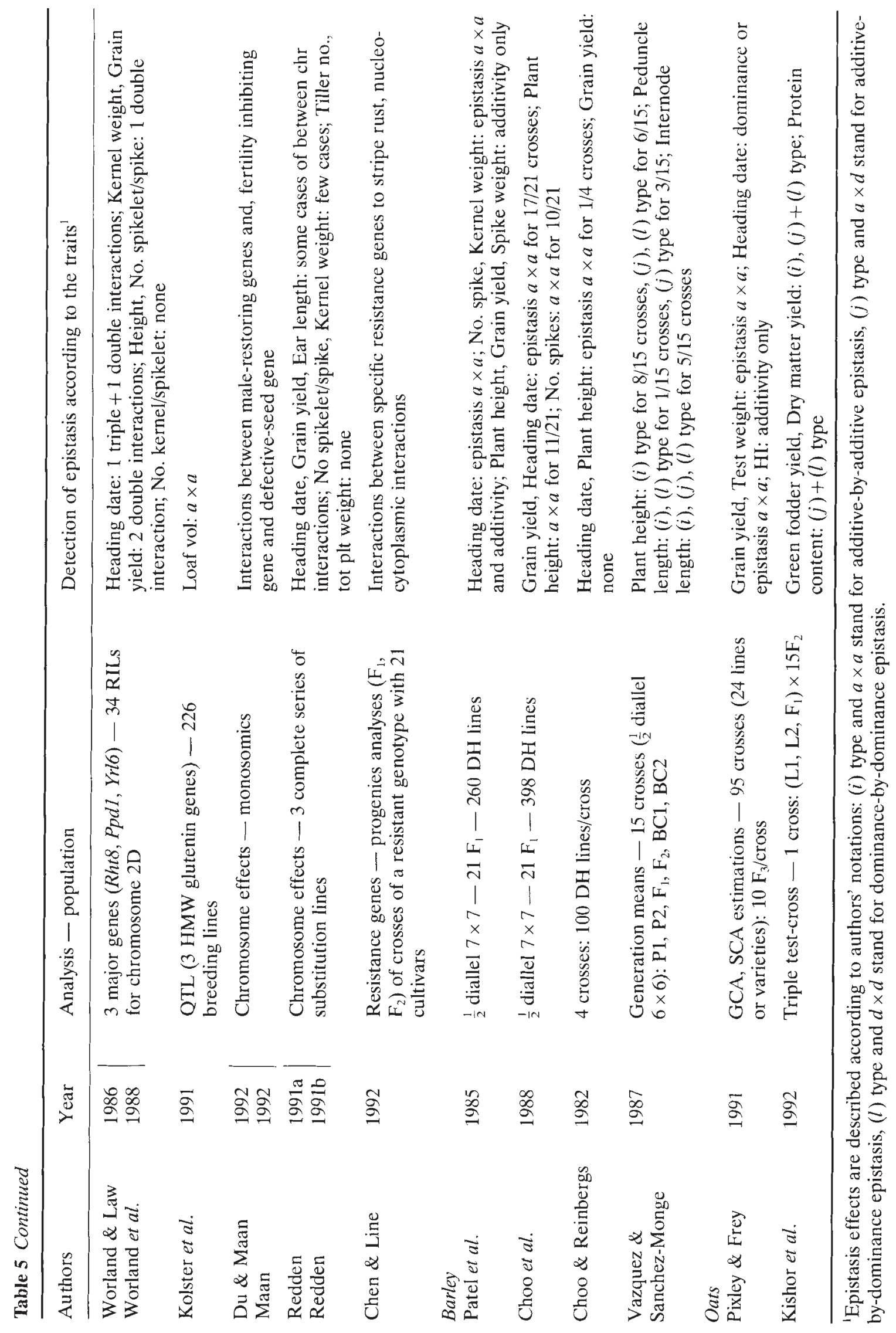

(c) The Genetical Society of Great Britain, Heredity, 79, 60-71. 
to a QTL or not. Further results from an $\mathrm{F}_{2}$ population of maize showed that more interactions between markers not associated with QTL were found than between markers associated with QTL (Maurice, 1994). This is in agreement with the hypothesis developed by Gallais \& Rives (1993): for statistical as well as for biological reasons, the QTL detected with the strongest effects are likely to be those that show little epistasis. Other types of epistasis concerning interactions between QTL and the genetic background have been observed in the recombinant inbred lines of a triple connected cross in maize (Charcosset et al., 1994).

Even if it were possible to assess accurately the variance components or genetic effects in a specific experiment, the genetic control of the traits could not be characterized for all possible environmental conditions. Indeed, the mechanisms involved in the elaboration of complex traits must be different according to the environment. In fact, if the value of a complex trait is determined by genes acting for general adaptation which interact with genes controlling adaptation to specific environments (Dillmann, 1992), epistasis should vary with the environment. The results obtained by Hayman (1958) for plant height in Nicotiana rustica confirm this statement. Theoretical studies in which a complex trait is modelled by a sigmoid transformation function, predict that complementary epistasis should arise in environments with low levels of resources (Dillmann, 1992). In our case, several of the traits (PH, NK/S, KW) showed less additivity and more epistasis in 1993 which provided stressed conditions during the reproductive period of the development cycle. Despite significant genotypeby-year interactions, our findings about additivity and epistasis were rather consistent from one year to the other. The literature does not provide simple and unique conclusions concerning epistasis for a given trait. The differences between the genetic backgrounds of the populations studied and between the experimental conditions must explain these ambiguous conclusions. It seems, nevertheless, that for most of the traits, except for the number of spikelets per spike and mean kernel weight, which are mainly additive, epistasis is often detected (in about three-quarters of the listed experiments).

The information on the relative amount of additivity and additive-by-additive epistasis combined with heritability can now be used to optimize recurrent selection strategies. The more epistatic a trait and the lower the heritability, the more efficient selection on highly inbred families is $\left(S_{2}\right.$ families or doubled-haploid lines). Given that grain yield, which is the most epistatic trait, has an epistatic variance almost twice as large as the additive variance, it should be selected using the doubled-haploid line method if possible or using the $S_{2}$ families method rather than the $S_{1}$ families method. On the other hand, kernel weight and plant height, which are predominantly additive, would be more effectively selected in an early generation after intercrossing.

\section{References}

BECKER, w. A. 1984. Manual of Quantitative Genetics, 4th edn. Academic Enterprises, Pullman, WA.

BRABANT, P., MANES, Y., TROTTET, M. AND PICARD, E. 1989. Corrélations génétiques, héritabilités et possibilités de sélection multilocale précoce sur le rendement chez le blé tendre d'hiver (Triticum aestivum L.). Agronomie, $\mathbf{9}$, $49-54$.

CARrillo, J. M., Rousset, M., QuAlset, C. O. AND KASARDA, D. D. 1990. Use of recombinant inbred lines of wheat for study of associations of high-molecularweight glutenin subunit alleles to quantitative traits. 1Grain yield and quality prediction tests. Theor. Appl. Genet., 79, 321-330.

CHAHAL, G. S. AND JiNKs, J. L. 1978. A general method of detecting the additive, dominance and epistatic variation that inbred lines can generate using a single tester. Heredity, 40, 117-125.

Charcosset, A., Causse, m., moreau, L. AND gallais, a. 1994. Investigation into the effect of genetic background on QTL expression using three connected maize recombinant inbred lines (RIL) populations. In: van Ooijen, J. W. and Jansen, J. (eds) Proc. 9th Meeting of the EUCARPIA Section Biometrics in Plant Breeding, 6-8 July 1994, Wageningen, the Netherlands, pp. 75-84. CPRO-DLO, Wageningen.

CHEN, X. M. AND LINE, R. F. 1992. Genes for resistance to strip rust in 'Tres' Wheat. Crop Sci., 32, 692-696.

CHOO, T. M. AND REINBERGS, E. 1982. Analysis of skewness and kurtosis for detecting gene interaction in a doubled haploid population. Crop Sci., 22, 231-235.

CHOO, T. M., CHRistie, B. R. AND REINBERGS, E. 1979. Doubled haploids for estimating genetic variances and a scheme for population improvement in self-pollinating crops. Theor. Appl. Genet., 54, 267-271.

CHOO, T. M., REINBERGS, E. AND Jul, P. Y. 1988. Comparison of $\mathrm{F}_{2}$ and $\mathrm{F}_{\infty}$ diallel analyses in barley. Genome, 30, $865-869$

COCKERHAM, C. C. 1984 . Additive by additive variance with inbreeding and linkage. Genetics, 108, 487-500.

CORNELIUS, P. L. 1975. Identity coefficients and covariances between relatives in a parent-offspring inbreeding system. Theor. Appl. Genet., 46, 201-212.

DHINDSA, G. S. AND BAINS, K. s. 1986 . Genotype $\times$ environment interaction for some morphological characters in triple test cross progenies of wheat. Crop Improv., 13, $168-171$. 
Dillmann, C. 1992. Organisation de la variabilité génétique chez les plantes: modélisation des effets d'interaction, conséquences sur la réponse a la sélection. Thèse, Institut National Agronomique Paris-Grignon.

DU, H. AND MAAN, S. S. 1992. Genetic analysis off malefertility restoration in wheat: VII. a fertility-inhibiting gene. Crop Sci., 32, 1414-1420.

GALlAIS, A. 1970. Covariances entre apparentés quelconques avec linkage et épistasie. II. Evolution en régime d'autofécondation. Ann. Génét. Sél. Anim., 2, 417-427.

GALLAIS, A. 1974. Covariances between arbitrary relatives with linkage and epistasis in the case of linkage disequilibrium. Biometrics, 30, 429-446.

GALLAIS, A. 1979. Le concept de valeur en lignées d'un génotype et son utilisation possible en sélection. Annls. Amél. Pl., 29, 1-22.

GALLAIS, A. 1990. Quantitative genetics of doubled haploid populations and application to the theory of line

": development. Genetics, 124, 199-206.

GALLAIS, A. 1993. Fields of efficiency of breeding methods for per se value or combining ability in plant breeding. Agronomie, 13, 467-480.

GALlais, A. AND RiVES, M. 1993. Detection, number and effects of QTLs for a complex character. Agronomie, 13, 723-738.

GıLlois, M. 1964. La relation d'identité en génétique. Thèse, Faculté des Sciences de Paris.

GOLDRINGER, I., BRABANT, P. AND KEMPTON, R. 1994. Adjustment for competition between genotypes in single-row-plot trials of winter wheat (Triticum aestivum L.). Pl. Breed., 112, 294-300.

GOLDRINGER, I., BRABANT, P. AND GALlais, A. 1996. Theoretical comparison of recurrent selection methods for the improvement of self-pollinated crops. Crop Sci., 36, 1171-1180.

GRIFFING, B. 1960. Theoretical consequences of truncation selection based on the individual phenotype. Aust. J. Biol. Sci., 13, 307-343.

HANUŠOVÁ, R., HSAM, S. L. K., BARTOŠ, P. AND ZELLER, F. J. 1996. Suppression of powdery mildew resistance gene Pm8 in Triticum aestivum L. (common wheat) cultivars carrying wheat-rye translocation T1BL.1RS. Heredity, 77, 383-387.

HARRIS, D. L. 1964. Genotypic covariances between inbred relatives. Genetics, 50, 1319-1348.

HAYMAN, B. I. 1958. The separation of epistatic from additive and dominance variation in generation means. Heredity, 12, 371-390.

JINKS, J. L., PERKINS, J. M. AND BREESE, E. L. 1969. A general method of detecting additive, dominance and epistatic variation for metrical traits. II. Application to inbred lines. Heredity, 24, 45-57.

KEARSEY, M. J. AND JINKS, J. L. 1968. A general method of detecting additive, dominance and epistatic variation for metrical traits. I. Theory. Heredity, 23, 403-409.

KETATA, H., SMITH, E. L., EDWARDS, L. H. AND MCNEW, R. W. 1976. Detection of epistasic, additive, and dominance variation in winter wheat (Triticum aestivum L. em Thell.). Crop Sci., 16, 1-4.
KISHOR, C., PARODA, R. S. AND JATASRA, D. S. 1992. Epistatic gene effects from the triple test-cross analysis in F2 population of oats for forage yield and quality. Indian J. Genet. \& Pl. Breed., 52, 50-54.

KNAPP, S. J., STROUP, w. w. AND ROSS, w. M. 1985. Exact confidence intervals for heritability on a progeny mean basis. Crop Sci., 25, 192-194.

KOLSTER, P., VAN EEUWIJK, F. A. AND VAN GELDER, W. M. J. 1991. Additive and epistatic effects of allelic variation at the high molecular weight glutenin subunit loci in determining the bread-making quality of breeding lines of wheat. Euphytica, 55, 277-285.

LEDENT, J. F. 1982. Morphology and yield in winter wheat grown in high yielding conditions. Crop Sci., 22, 1115-1120.

MAAN, s. s. 1992. Genetic analyses of male fertility restoration in wheat: VI. a defective-seed gene. Crop Sci., 32, 1408-1413.

MASLE, J., DOUSSINAUlT, G. AND SUN, B. 1989. Response of wheat genotypes to temperature and photoperiod in natural conditions. Crop Sci., 29, 712-721.

MATHER, K. AND Jinks, J. L. 1971. Biometrical Genetics. The Study of Continuous Variation, 2nd edn. Chapman and Hall, London.

MAURICE, A. 1994. Utilisation des marqueurs moléculaires pour l'analyse du déterminisme génétique des caractères complexes et l'optimisation des schémas de sélection chez le maïs (Zea mays L.). Thèse de Docteur de l'INA-PG.

MCClUNG, A. M., CANTREll, R. G., QUICK, J. S. AND GREGORY, R. S. 1986. Influence of the Rht1 semidwarf gene on yield, yield components, and grain protein in durum Wheat. Crop Sci., 26, 1095-1099.

MCKENDRY, A. L., McVETTY, P. B. E. AND EVANS, L. E. 1988. Inheritance of grain protein concentration, grain yield, and related traits in spring wheat (Triticum aestivum L.). Genome, 30, 857-864.

MERRIT, R. G. 1988. Inheritance of culm number in two uniculm $\times$ multiculm wheat crosses. Euphytica, 38, $105-111$.

NANDA, G. S., SINGH, P. AND GILL, K. S. 1982. Epistatic, additive and dominance variation in a triple test cross of bread wheat (Triticum aestivum L.). Theor. Appl. Genet., 62, 49-52.

NANDA, G. S., SINGH, G. AND CHAND, K. 1989. Detection of components of genetic variation and prediction of the frequencies of transgressive segregants in bread wheat (Triticum aestivum L.). J. Genet. Breed., 44, 63-66.

PATEl, J. D., BAINS, K. S. AND Chahal, G. S. 1985. Simultaneous estimation of additive and dominance genetic variance in heterozygous and homozygous populations. Can. J. Genet. Cytol., 27, 114-120.

PAWAR, I. S., PARODA, R. S. AND SINGH, s. 1988. Gene effects for six metric traits in four spring wheat crosses. Indian J. Genet. \& Pl. Breed., 48, 195-199.

PIXLEY, K. V. AND FREY, K. J. 1991. Combining ability for test weight and agronomic traits of oat. Crop Sci., 31, 1448-1451.

REDDEN, R, 1991a. the effect of epistasis on chromosome mapping of quantitative characters in wheat. 1 - Time to 
spike emergence. Aust. J. Agric. Res., 42, 1-11.

REDDEN, R. 1991b. the effect of epistasis on chromosome mapping of quantitative characters in wheat. 2- Agronomic characters. Aust. J. Agric. Res., 42, 335-345.

RousSeT, M., CARRILlo, J. M., QUALSET, C. O. AND KARSADA, D. D. 1992. Use of recombinant inbred lines of wheat for study of associations of high-molecularweight glutenin subunit alleles to quantitative traits. Theor. Appl. Genet., 83, 403-412.

SCHEINBERG, E. 1966. The sampling variance of the correlation coefficients estimated in genetic experiments. Biometrics, 22, 187-191.

SINGH, s. 1990. Bias caused by epistasis in the estimates of additive and dominance components and their interactions with environment in wheat. Indian J. Genet. \& Pl. Breed, , 50, 157-160.

SINGH, 1., PARODA, R. S. AND SINGH, S. 1986. Genotype $\times$ environment interaction analysis of triple-test-cross progenies for some metric traits in wheat. Crop Improv, 13, 117-121.

SINGH, 1., PAWAR, 1. S. AND SINGH, s. 1988. Detection of additive, dominance and epistatic components of genetic variation for some metric traits in wheat. Genet. Agr., 42, 371-378.

SINGH, 1., PAWAR, 1. S. AND SINGH, S. 1989. Detection of genotype $\times$ environment interaction in spring wheat through triple test cross analysis. Crop Improv., 16, 34-37.

SINHA, B., SINGH, R. M. AND SINGH, U. P. 1991. Genetics of leaf blight resistance in wheat. Theor. Appl. Genet., 82, 399-404.

SNAPE, J. W. AND SIMPSON, E. 1981. The genetical expectations of doubled haploid lines derived from different filial generations. Theor. Appl. Genet., 60, 123-128.

STRIVASTAVA, R. B., SHARMA, S. C. AND YUNUS, M. 1992. Additive and nonadditive gene effects for yield and yield components in two crosses of wheat. Indian $J$. Genet. \& Pl. Breed., 52, 297-301.

THOMAS, G., DOUSSINAUlt, G. AND trotTET, M. 1991. Méthodologie de l'amélioration du blé tendre (Triticum aestivum L.). II. Etude et analyse des deux premiers cycles de selection recurrente. Agronomie, 11, 457-472.

VAZQUEZ, J. F. AND SANCHEZ-MONGE, E. 1987. Correlations, epistasis, and heterosis of plant height and internode length in barley. Genome, 29, 532-536.

VERMA, s. S. AND YUNUS, M. 1986. Role of epistasis in the analysis of genetic components of variance in breadwheat. Ind. J. Agric. Sci., 56, 687-689.

VIRK, D. S. AND JINKS, J. L. 1977. The consequences of using inadequate testers in the simplified triple testcross. Heredity, 38, 237-251.

VIRK, D. S., VIRK, P. S. AND AULAKH, H. s. 1989. Detection of additive, dominance and epistatic variation using single tester analysis in breadwheat. Indian J. Genet. \& Pl. Breed., 49, 213-217.

WORLAND, A. J. AND LAW, C. N. 1986. Genetic analysis of chromosome $2 \mathrm{D}$ of wheat. 1. The location of genes affecting height, day length insensitivity, hybrid dwarfism and yellow rust resistance. Z. PfZücht., 96, 331-345.

WORLAND, A. J., LAW, C. N. AND PETROVIC, s. 1988. Pleiotropic effects of the chromosome 2D genes $P p d 1$, Rht8 and Yr16. In: Miller, T. E. and Koebner, R. M. D. (eds) Proc. 7th Int. Wheat Genet. Symp., Inst. Plant Sci. Res., Cambridge, England, 1988, pp. 669-674. IPSR, Cambridge.

XIN, Z. Y., LAW, C. N. AND WORLAND, A. J. 1988. Studies of the effects of the vernalization responsive genes on the chromosomes of homoeologous group 5 of wheat. In: Miller, T. E. and Koebner, R. M. D. (eds) Proc. 7th Int. Wheat Genet. Symp., Inst. Plant Sci. Res., Cambridge, England, 1988, pp. 675-680. 